\title{
Weather effects on hand, foot, and mouth disease at individual level: a case-crossover study
}

\author{
Zhicheng Du', Shao Lin², Tia Marks², Wangjian Zhang ${ }^{2}$, Te Deng ${ }^{3}$, Shicheng Yu ${ }^{4}$ and Yuantao Hao ${ }^{1 *}$ (D)
}

\begin{abstract}
Background: Hand, foot, and mouth disease (HFMD) raises an urgent public health issue in the Asia-Pacific region, especially in China. The associations between weather factors and HFMD have been widely studied but with inconsistent results. Moreover, previous studies utilizing ecological design could not rule out the bias of exposure misclassification and unobserved confounders.

Methods: We used case-crossover analysis to assess the associations of weather factors on HFMD. Individual HFMD cases from 2009 to 2012 in Guangdong were collected and cases located within $10 \mathrm{~km}$ of the meteorological monitoring sites were included. Lag effects were examined through the previous 7 days. In addition, we explored the variability by changing the distance within $20 \mathrm{~km}$ and $30 \mathrm{~km}$.

Results: We observed associations between HFMD and weather factors, including temperature and relative humidity. An approximately U-shaped relationship was observed for the associations of temperature on HFMD across the same day and the previous 7 days, while an approximately exponential-shaped was seen for relative humidity. Statistically significant increases in rates of HFMD were associated with each 10-unit increases in temperature [Excess rate (ER): 7.7\%; 95\% Confidence Interval (Cl): 3.9, 11.7\%] and relative humidity (ER: 1.9\%; 95\% Cl: 0.7, 3.0\%) on lag days 0-6, when assessing within $10 \mathrm{~km}$ of the monitoring sites. Potential thresholds for temperature $\left(30.0^{\circ} \mathrm{C}\right)$ and relative humidity (70.3\%) detected showed associations with HFMD. The associations remained robust for $20 \mathrm{~km}$ and $30 \mathrm{~km}$.

Conclusions: Our study found that temperature and relative humidity are significantly associated with the increased rates of HFMD. Thresholds and lag effects were observed between weather factors and HFMD. Our findings are useful for planning on targeted prevention and control of HFMD.
\end{abstract}

Keywords: Hand, foot, and mouth disease, Case-crossover, Weather effect

\section{Background}

Hand, foot, and mouth disease (HFMD) is a pediatric infectious disease causing outbreaks worldwide [1]. At least in mainland China, HFMD was reported as the infectious disease with highest yearly incidence with a 9 year average $(114.48$ per 100,000) from 2004 to 2013 [2]. Although HFMD cases are often mild, severe and fatal cases among children are not rare [3]. HFMD has become a vital public health concern due to its threat to children and its huge burdens on society.

\footnotetext{
* Correspondence: haoyt@mail.sysu.edu.cn

${ }^{1}$ Department of Medical Statistics and Epidemiology, School of Public Health, Sun Yat-sen University, Guangzhou 510080, China

Full list of author information is available at the end of the article
}

Weather factors (e.g., temperature and relative humidity) have been widely reported as having associations with HFMD in previous studies. Temperature was estimated to have a risk ratio of 1.30 (95\% CI: $1.23,1.37)$ at the 91st percentile compared to the 50th [4]. The commonly hot days were found to increase HFMD burdens with a relative risk peaking at around 6 days of lag [5]. One of our preceding studies also found that temperature (relative risk, RR: 1.039; 95\% CI: 1.028 , 1.050 ) and relative humidity (RR: 1.015 ; $95 \%$ CI: 1.010 , 1.021) were statistically associated with HFMD incidence using a Bayesian spatiotemporal model [6].

Biases from exposure misclassification were major limitations in previous studies. For studies using a time- 
series design or other ecological designs, the mean value of weather factors from limited monitoring sites were usually assigned to all HFMD cases located throughout a large region no matter how far they lived from the monitor (e.g., a city or a province) [7-11]. Including cases farther away from monitoring sites and using the same values as those near the monitoring sites can result in an underestimation due to the bias of exposure misclassification or exposure error [12-15]. Moreover, these studies were analyzed at the population level (i.e., ecological design) [16], which usually assigns the mean value of weather factors to a group of subjects rather than a single subject. In addition, these studies might miss some important confounders at individual levels such as age, gender, and race/ethnicity.

To address these biases of exposure misclassification and unobserved confounders, we conducted this casecrossover study to examine the association between short-term (within 1 week) increases in weather factors and HFMD, weather factors' lag effects (0-7 days) and potential thresholds on HFMD, and validate the exposurehealth association by evaluating difference residential distances to monitor sites $(10,20$, and $30 \mathrm{~km})$.

\section{Methods}

\section{Study design}

To estimate the associations between HFMD and temperature and relative humidity, we used a casecrossover design and conditional logistic regression models [17]. The fixed 28-day-window case-crossover approach was used in this study and was recently used in previous studies of environmental health [18, 19]. Each HFMD case was defined as "case" in the matched case-control study. Each HFMD case in other weeks with the same calendar month and weekday when they did not get infection served as their own controls. Therefore, each HFMD case were compared to three or four controls within the same month. And the outcome in this study was a dichotomous variable with the "case" coded as " 1 " and the "control" coded as " 0 ". This design contrasts weather factors immediately before the HFMD cases onset to the weather factors of their own controls.

\section{Study population and HFMD cases data}

Information on HFMD cases were obtained from the China Center for Disease Control and Prevention (China CDC), which we have used previously [3, 10]. HFMD has been included as a notifiable infectious disease since May 2008. Data on HFMD cases are collected in a legislatively mandated database, covering almost all cases in China [20]. HFMD data include patient information on the laboratory testing results and severity, as well as demographic characteristics including date of birth, gender, residential address, occupation, and onset information.
Anyone who reports cases to the system must be strictly certified to ensure accuracy and completeness of data. We geocoded the residential address for all cases using the Geocoder service of Baidu Maps [21].

HFMD cases aged $<18$ years old with an onset date from January 1, 2009 to December 31, 2012 for residents of Guangdong were obtained. We then included all study subjects living within 10,20 , and $30 \mathrm{~km}(\mathrm{~km})$ of any of the 36 weather monitoring sites in Guangdong (described below), leaving $N=100,669,280,957,490,497$ available cases for analyses. Missing values in virus types and severity were recoded as "missing". No missing data on other variables was observed for the HFMD cases data. This study was reviewed and approved by the Institutional Review Board at the School of Public Health, Sun Yat-Sen University.

\section{Weather data}

Daily temperature and relative humidity data were retrieved from the National Meteorological Information Center (http://data.cma.cn/) for each of the 36 monitoring sites (Fig. 1) where measurements were collected (19 out of 21 cities in Guangdong): Shaoguan, Qingyuan, Heyuan, Meizhou, Zhaoqing, Guangzhou, Dongguan, Huizhou, Jieyang, Shantou, Maoming, Yunfu, Jiangmen, Zhongshan, Zhuhai, Shenzhen, Shanwei, Zhanjiang and Yangjiang. At each site, hourly temperature and relative humidity were measured using platinum resistance temperature detectors and capacitive thin-film polymer sensors, respectively. In our study, 24-h daily averages were used. We assigned the measurements of each monitoring site to the cases within 10,20 , and $30 \mathrm{~km}$. Consistent with previous studies $[5,7$, $18,22]$, we calculated the mean of weather factors for the onset day (lag day 0), and previous 2 to 14 days (lag days $0-1$ to $0-13)$ to estimate the cumulative lagged effects. Another reasoning for setting lag days is HFMD has an incubation period of 3-7 days [23]. No missing data was observed for the weather data.

\section{Statistical analyses}

Using descriptive analyses, we assessed the distribution of case characteristics (sex, age, occupation, virus, and severity) by distance away from each meteorological monitoring site (within 10,20 , and $30 \mathrm{~km}$ ).

Conditional logistic regression model was used to estimate the relative risk (RR) and 95\% confidence interval (CI) of HFMD associated with each 10-unit increases in temperature and relative humidity during each lag period. The conditional logistic regression model can then be specified as below:

$$
\operatorname{logit}(p)=\beta X+a_{\text {stratum }(i)}
$$

where, $p$ is the probability of being a case. $X$ is the 


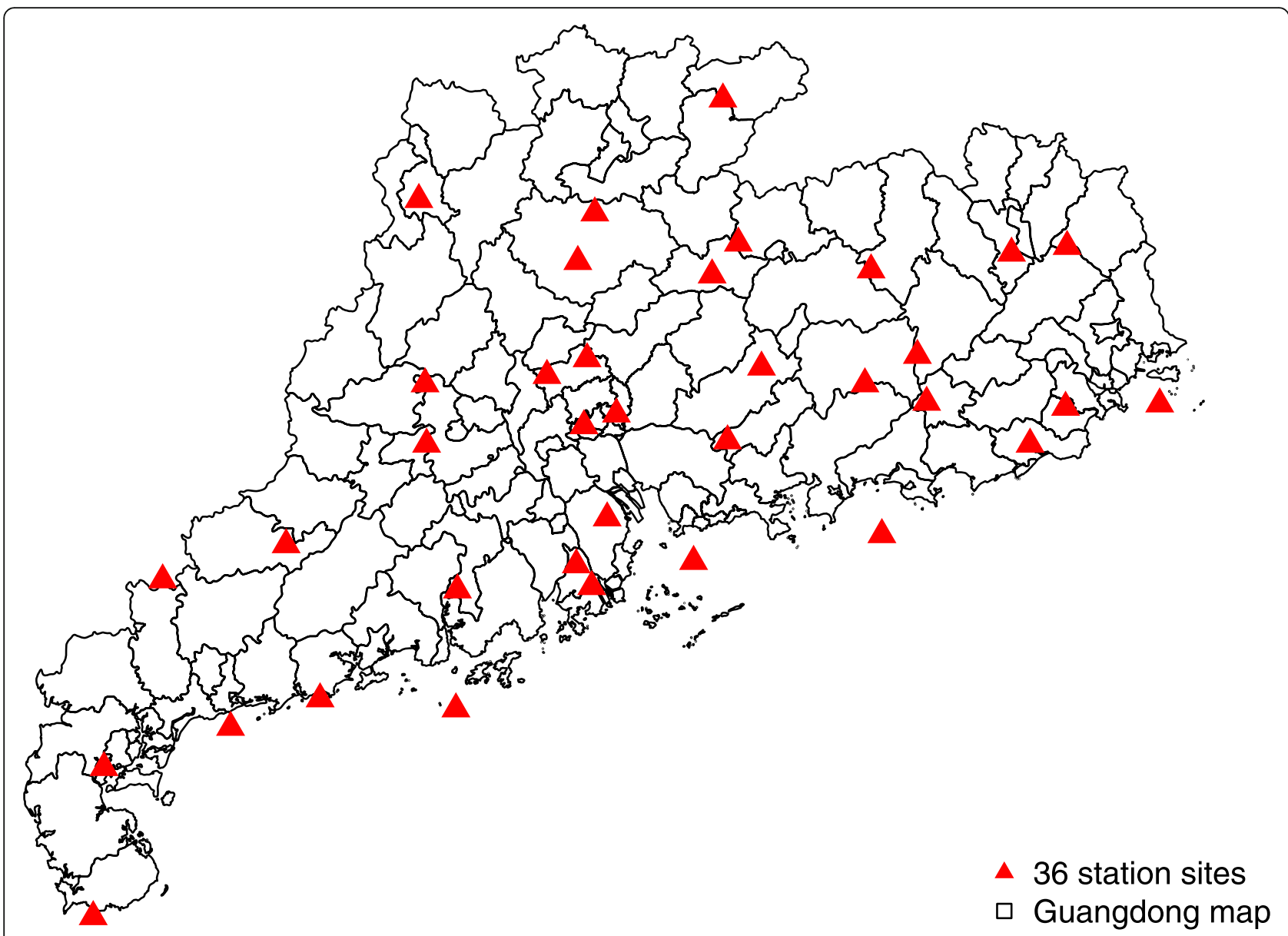

Fig. 1 Locations of 36 national meteorological monitoring sites in Guangdong. This map was downloaded from OpenStreetMap (The cartography in the OpenStreetMap map tiles is licensed under CC BY-SA (www.openstreetmap.org/copyright, @ OpenStreetMap contributor). The licence terms can be found on the following link: http://creativecommons.org/licenses/by-sa/2.0/) and processed by and R version 3.4.3 (R Core Team, Vienna, Austria, 2017, https://www.R-project.org)

weather factors (i.e., temperature or relative humidity). $\beta$ is the regression coefficients, and they can be converted to RR by $\mathrm{e}^{\beta}$. stratum (i) indicates each case-control pair, and $\alpha$ is the stratum constant.

Moreover, we calculated the excess rate (ER) using (RR$1) \times 100 \%$ to make it easier to interpret and compare. Piecewise linear regression [24] was used to identify the change points (thresholds at which the association between HFMD and weather factors change) in the association between HFMD and weather factors. We also conducted the subgroup analyses by sex, age, and occupation to estimate the ERs among different population groups on lag days 0-6 within $10 \mathrm{~km}$. $\mathrm{R}$ version 3.5.1 ( $\mathrm{R}$ Foundation for Statistical Computing, Vienna, Austria; https://www.r-project.org/) was used for all data managements and statistical analyses in this study.

\section{Results}

Table 1 shows case characteristics, by distance away from monitoring sites. Of the 921,499 HFMD cases during the study period, $10.92 \%$ of cases were included within $10 \mathrm{~km}$ of the monitoring sites, $30.49 \%$ cases for $20 \mathrm{~km}$, and $53.23 \%$ cases for $30 \mathrm{~km}$. Across different distances, cases were primarily male (exceed 63\%), 3 years old and younger (exceed 80\%), home-care children (exceed 69\%), and mild cases (exceed 99\%). With the exception of the missing values, the viruses of Coxsackievirus A16 (CoxA16), Enterovirus 71 (EV71), and others showed similar values of proportions. However, the proportions of different characteristics showed statistical difference among different distances due to the large sample size.

Table 2 describes the weather factors using mean and median statistics. For weather factors without lags (lag day 0), temperature (mean of $10 \mathrm{~km}: 26.7^{\circ} \mathrm{C}$ vs. $26.6^{\circ} \mathrm{C}$ ) of case periods were slightly higher than control periods, while the relative humidity ( $77 \%$ vs. $77.4 \%$ ) was slightly lower during case periods than control periods. For weather factors with lag days 0-6, temperature had the same distribution as lag day 0 , while the relative humidity was equal (77.4\%) during both case and control periods. For 
Table 1 Cases characteristics and within different distance of the monitoring sites

\begin{tabular}{|c|c|c|c|c|c|}
\hline & $\begin{array}{l}\text { Total } \\
\text { N (\%) }\end{array}$ & $\begin{array}{l}10 \mathrm{~km} \\
\mathrm{~N}(\%)\end{array}$ & $\begin{array}{l}20 \mathrm{~km} \\
\mathrm{~N}(\%)\end{array}$ & $\begin{array}{l}30 \mathrm{~km} \\
\mathrm{~N}(\%)\end{array}$ & $P$ value* \\
\hline Sample size & $921,499(100)$ & $100,669(10.92)$ & $280,957(30.49)$ & $490,497(53.23)$ & \\
\hline Sex & & & & & 0.016 \\
\hline female & $327,858(35.58)$ & 36,770 (36.53) & $101,648(36.18)$ & $176,843(36.05)$ & \\
\hline male & $593,641(64.42)$ & $63,899(63.47)$ & $179,309(63.82)$ & $313,654(63.95)$ & \\
\hline Age & & & & & $<0.001$ \\
\hline$(0,1]$ & $402,160(43.64)$ & 39,806 (39.54) & $119,233(42.44)$ & $209,734(42.76)$ & \\
\hline$(1,3]$ & 362,151 (39.30) & $43,096(42.81)$ & $115,171(40.99)$ & $199,021(40.58)$ & \\
\hline$(3,5]$ & $112,854(12.25)$ & $13,051(12.96)$ & 34,217 (12.18) & 59,709 (12.17) & \\
\hline$(5,18]$ & $44,334(4.81)$ & $4716(4.68)$ & $12,336(4.39)$ & 22,033 (4.49) & \\
\hline Occupation & & & & & $<0.001$ \\
\hline student & $27,126(2.94)$ & $2844(2.83)$ & 7616 (2.71) & $13,786(2.81)$ & \\
\hline preschool & $182,051(19.76)$ & $27,330(27.15)$ & $64,607(23.00)$ & $111,652(22.76)$ & \\
\hline home-care & $709,310(76.97)$ & $70,364(69.90)$ & $208,133(74.08)$ & $363,730(74.16)$ & \\
\hline others & $3012(0.33)$ & $131(0.13)$ & $601(0.21)$ & $1329(0.27)$ & \\
\hline Virus & & & & & $<0.001$ \\
\hline CoxA16 & $6113(0.66)$ & 2345 (2.33) & $4012(1.43)$ & 4806 (0.98) & \\
\hline EV71 & 8207 (0.89) & $1848(1.84)$ & 3747 (1.33) & 5353 (1.09) & \\
\hline others & $7122(0.77)$ & $2843(2.82)$ & $4871(1.73)$ & 5840 (1.19) & \\
\hline missing & $900,057(97.67)$ & $93,633(93.01)$ & $268,327(95.50)$ & 474,498 (96.74) & \\
\hline Severity & & & & & $<0.001$ \\
\hline mild & $916,653(99.47)$ & $100,213(99.55)$ & 279,505 (99.48) & $487,676(99.42)$ & \\
\hline severe & $3737(0.41)$ & $364(0.36)$ & $1152(0.41)$ & $2244(0.46)$ & \\
\hline missing & $1109(0.12)$ & $92(0.09)$ & $300(0.11)$ & $577(0.12)$ & \\
\hline
\end{tabular}

${ }^{*}$ Chi-square test

weather factors with lag days $0-13$, temperature had the same level $\left(26.6{ }^{\circ} \mathrm{C}\right)$ between case periods and control periods, while the relative humidity $(77.6 \%$ vs. $77.3 \%)$ was slightly higher during case periods than control periods.

Table 3 and Fig. 2 show the excess rates of HFMD associated with each 10-unit increases in weather factors by lag days. When assessing within $10 \mathrm{~km}$ of the monitoring sites, each 10-unit increases in temperature for all lag days were associated with $5.0-24.2 \%$ increased rates of HFMD. An approximately U-shaped relationship was observed for the relationship between HFMD and temperature. However, the excess rates of HFMD went up exponentially with each 10 -unit increases in relative humidity across lag days, from $-5.6 \%$ (lag day 0 ) to $19.3 \%$ (lag days $0-13$ ). Overall, statistically positive excess rates were found since lag days $0-6$ for both weather factors. As seen in the sensitivity analyses, similar results were also observed for $20 \mathrm{~km}$ and $30 \mathrm{~km}$. For the results of subgroup analyses by sex, age, and occupation (see Additional file 1: Table S1). We found that males, children younger than 1 year of age, and home-care children were more sensitive to the effect of temperature and relative humidity. In addition, an earlier effect was observed among the serotype-specific analyses with the limited number of cases (see Additional file 1: Table S2).

Figure 3 shows the change point of association between HFMD and weather factors on lag days 0-6 within $10 \mathrm{~km}$ of the monitoring sites. The RR of HFMD increased with the range of temperature and relative humidity. The change points for temperature and relative humidity were $30.0^{\circ} \mathrm{C}$ and $70.3 \%$, respectively. Different slopes were found before and after the change points, and the later slopes were more precipitous.

\section{Discussion}

Using a case-crossover design, the present study included 0.2-0.7 million HFMD cases determined by distances away from monitoring sites through January 2009 to December 2012, accounting for 11-53\% of reported cases in Guangdong. Similar demographic characteristics of cases across different distances away from monitoring sites indicated a random spatial distribution of HFMD 
Table 2 Distribution of weather factors for case periods and control periods

\begin{tabular}{|c|c|c|c|c|c|c|}
\hline \multirow[t]{2}{*}{ Lag } & \multirow[t]{2}{*}{ Weather factor } & \multirow[t]{2}{*}{ Distance } & \multicolumn{2}{|l|}{ Case } & \multicolumn{2}{|l|}{ Control } \\
\hline & & & Mean $\pm S D^{*}$ & Median $\left(\mathrm{IQR}^{*}\right)$ & Mean \pm SD & Median (IQR) \\
\hline \multirow[t]{6}{*}{0} & \multirow[t]{3}{*}{ Temperature $\left({ }^{\circ} \mathrm{C}\right)$} & $10 \mathrm{~km}$ & $26.7 \pm 5.4$ & $27.6(23.8,30.4)$ & $26.6 \pm 5.5$ & $27.5(23.7,30.3)$ \\
\hline & & $20 \mathrm{~km}$ & $26.8 \pm 5.6$ & $27.7(23.8,30.5)$ & $26.7 \pm 5.6$ & $27.6(23.7,30.4)$ \\
\hline & & $30 \mathrm{~km}$ & $26.9 \pm 5.5$ & $27.7(23.9,30.5)$ & $26.8 \pm 5.6$ & $27.7(23.7,30.5)$ \\
\hline & \multirow[t]{3}{*}{ Relative humidity (\%) } & $10 \mathrm{~km}$ & $77 \pm 11$ & $78(71,85)$ & $77.4 \pm 10.9$ & $79(71,85)$ \\
\hline & & $20 \mathrm{~km}$ & $76.7 \pm 10.9$ & $78(70,84)$ & $77.1 \pm 10.8$ & $78(71,85)$ \\
\hline & & $30 \mathrm{~km}$ & $76.7 \pm 10.9$ & $78(70,84)$ & $77 \pm 10.9$ & $78(71,85)$ \\
\hline \multirow[t]{6}{*}{$0-6$} & \multirow[t]{3}{*}{ Temperature $\left({ }^{\circ} \mathrm{C}\right)$} & $10 \mathrm{~km}$ & $26.7 \pm 5$ & $28(23.9,29.9)$ & $26.6 \pm 5.1$ & $28(23.8,30)$ \\
\hline & & $20 \mathrm{~km}$ & $26.7 \pm 5.1$ & $28(23.8,30.1)$ & $26.7 \pm 5.2$ & $28(23.8,30.1)$ \\
\hline & & $30 \mathrm{~km}$ & $26.8 \pm 5.1$ & $28.1(23.9,30.1)$ & $26.8 \pm 5.1$ & $28.1(23.8,30.2)$ \\
\hline & \multirow[t]{3}{*}{ Relative humidity (\%) } & $10 \mathrm{~km}$ & $77.4 \pm 8.2$ & $78.6(73.1,83.3)$ & $77.4 \pm 8.3$ & $78.6(72.9,83.3)$ \\
\hline & & $20 \mathrm{~km}$ & $77.2 \pm 8.1$ & $78.3(72.7,83)$ & $77 \pm 8.3$ & $78.1(72.6,83)$ \\
\hline & & $30 \mathrm{~km}$ & $77.1 \pm 8.2$ & $78.3(72.6,83)$ & $77 \pm 8.3$ & $78.1(72.4,83)$ \\
\hline \multirow[t]{6}{*}{$0-13$} & \multirow[t]{3}{*}{ Temperature $\left({ }^{\circ} \mathrm{C}\right)$} & $10 \mathrm{~km}$ & $26.6 \pm 4.8$ & $28(23.9,30)$ & $26.6 \pm 4.9$ & $28(23.6,30)$ \\
\hline & & $20 \mathrm{~km}$ & $26.7 \pm 4.9$ & $28(23.9,30.1)$ & $26.7 \pm 5$ & $28(23.6,30.2)$ \\
\hline & & $30 \mathrm{~km}$ & $26.8 \pm 4.9$ & $28.1(23.9,30.2)$ & $26.7 \pm 5$ & $28(23.7,30.2)$ \\
\hline & \multirow[t]{3}{*}{ Relative humidity (\%) } & $10 \mathrm{~km}$ & $77.6 \pm 7$ & $78.9(73.8,82.5)$ & $77.3 \pm 7.2$ & $78.6(73.3,82.4)$ \\
\hline & & $20 \mathrm{~km}$ & $77.3 \pm 7$ & $78.5(73.2,82.3)$ & $77 \pm 7.2$ & $78.1(72.8,82.1)$ \\
\hline & & $30 \mathrm{~km}$ & $77.3 \pm 7.1$ & $78.4(73.1,82.3)$ & $76.9 \pm 7.2$ & $78(72.6,82.1)$ \\
\hline
\end{tabular}

*SD Standard deviation, IQR Interquartile range

cases, which showed the representativeness of the study population. While relative humidity was higher during control periods across different distances away from monitoring sites, temperature was higher during case periods. Interquartile range increases in temperature and relative humidity imposed statistically significant excess rates on HFMD. Increased rates of 4.7 (95\%CI: 2.4, 7.1) for temperature and 1.9 (95\% CI: $0.8,3.1)$ for relative humidity were associated with HFMD on lag days 0-6 within $10 \mathrm{~km}$ of the monitoring sites.

Table 3 Excess rates of HFMD associated with each 10-unit increases in weather factors

\begin{tabular}{|c|c|c|c|c|c|c|}
\hline \multirow{3}{*}{ Lag day } & \multicolumn{2}{|l|}{$10 \mathrm{~km}$} & \multicolumn{2}{|l|}{$20 \mathrm{~km}$} & \multicolumn{2}{|l|}{$30 \mathrm{~km}$} \\
\hline & Temperature $\left({ }^{\circ} \mathrm{C}\right)$ & Relative humidity (\%) & Temperature $\left({ }^{\circ} \mathrm{C}\right)$ & Relative humidity (\%) & Temperature $\left({ }^{\circ} \mathrm{C}\right)$ & Relative humidity (\%) \\
\hline & ER $(95 \% \mathrm{Cl})^{*}$ & ER $(95 \% \mathrm{Cl})$ & ER $(95 \% \mathrm{Cl})$ & ER $(95 \% \mathrm{Cl})$ & ER $(95 \% \mathrm{Cl})$ & ER $(95 \% \mathrm{Cl})$ \\
\hline 0 & $14.6(11.9,17.4)$ & $-5.6(-6.3,-4.9)$ & $14.8(13.2,16.4)$ & $-5.2(-5.7,-4.8)$ & $13.9(12.8,15.2)$ & $-5.0(-5.3,-4.7)$ \\
\hline $0-1$ & $10.1(7.2,13.0)$ & $-5.6(-6.3,-4.8)$ & $10.3(8.6,12.1)$ & $-5.2(-5.7,-4.8)$ & $9.8(8.5,11.1)$ & $-5.1(-5.4,-4.7)$ \\
\hline $0-2$ & $6.5(3.5,9.6)$ & $-5.4(-6.2,-4.6)$ & $6.8(5.0,8.6)$ & $-5.2(-5.6,-4.7)$ & $6.5(5.2,7.9)$ & $-5.1(-5.5,-4.7)$ \\
\hline $0-3$ & $5.3(2.1,8.6)$ & $-4.6(-5.5,-3.7)$ & $4.9(3.1,6.8)$ & $-4.3(-4.9,-3.8)$ & $4.7(3.3,6.1)$ & $-4.3(-4.7,-3.9)$ \\
\hline $0-4$ & $5.0(1.6,8.5)$ & $-2.9(-3.9,-2.0)$ & $4.9(2.9,6.9)$ & $-2.8(-3.3,-2.2)$ & $4.7(3.2,6.2)$ & $-2.7(-3.2,-2.3)$ \\
\hline $0-5$ & $5.8(2.2,9.5)$ & $-0.7(-1.7,0.4)$ & $5.9(3.7,8.0)$ & $-0.4(-1.0,0.3)$ & $5.8(4.3,7.4)$ & $-0.4(-0.9,0.1)$ \\
\hline $0-6$ & $7.7(3.9,11.7)$ & $1.9(0.7,3.0)$ & $8.0(5.8,10.4)$ & $2.3(1.7,3.0)$ & $8.1(6.4,9.9)$ & $2.3(1.8,2.8)$ \\
\hline $0-7$ & $11.0(6.8,15.4)$ & $4.8(3.6,6.0)$ & $11.3(8.8,13.8)$ & $5.4(4.7,6.2)$ & $11.5(9.6,13.4)$ & $5.3(4.7,5.9)$ \\
\hline $0-8$ & $15.7(11.1,20.5)$ & $7.7(6.4,9.1)$ & $15.8(13.0,18.5)$ & $8.4(7.6,9.2)$ & $16.2(14.2,18.3)$ & $8.2(7.6,8.8)$ \\
\hline $0-9$ & $19.3(14.4,24.5)$ & $10.6(9.1,12.0)$ & $20.1(17.1,23.1)$ & $11.2(10.4,12.1)$ & $21.0(18.8,23.2)$ & $11.0(10.3,11.6)$ \\
\hline $0-10$ & $22.1(16.9,27.6)$ & $13.1(11.5,14.6)$ & $23.6(20.4,26.8)$ & $13.7(12.8,14.7)$ & $24.9(22.5,27.3)$ & $13.4(12.7,14.1)$ \\
\hline $0-11$ & $23.6(18.1,29.3)$ & $15.3(13.6,16.9)$ & $25.2(21.9,28.6)$ & $15.9(14.9,16.9)$ & $27.2(24.7,29.8)$ & $15.4(14.7,16.2)$ \\
\hline $0-12$ & $24.1(18.5,30.1)$ & $17.3(15.6,19.1)$ & $25.9(22.5,29.4)$ & $17.9(16.8,18.9)$ & $28.4(25.8,31.1)$ & $17.3(16.5,18.1)$ \\
\hline $0-13$ & $24.2(18.4,30.3)$ & $19.3(17.5,21.2)$ & $25.8(22.3,29.4)$ & $19.8(18.7,20.9)$ & $28.6(25.9,31.4)$ & $19.1(18.3,20.0)$ \\
\hline
\end{tabular}



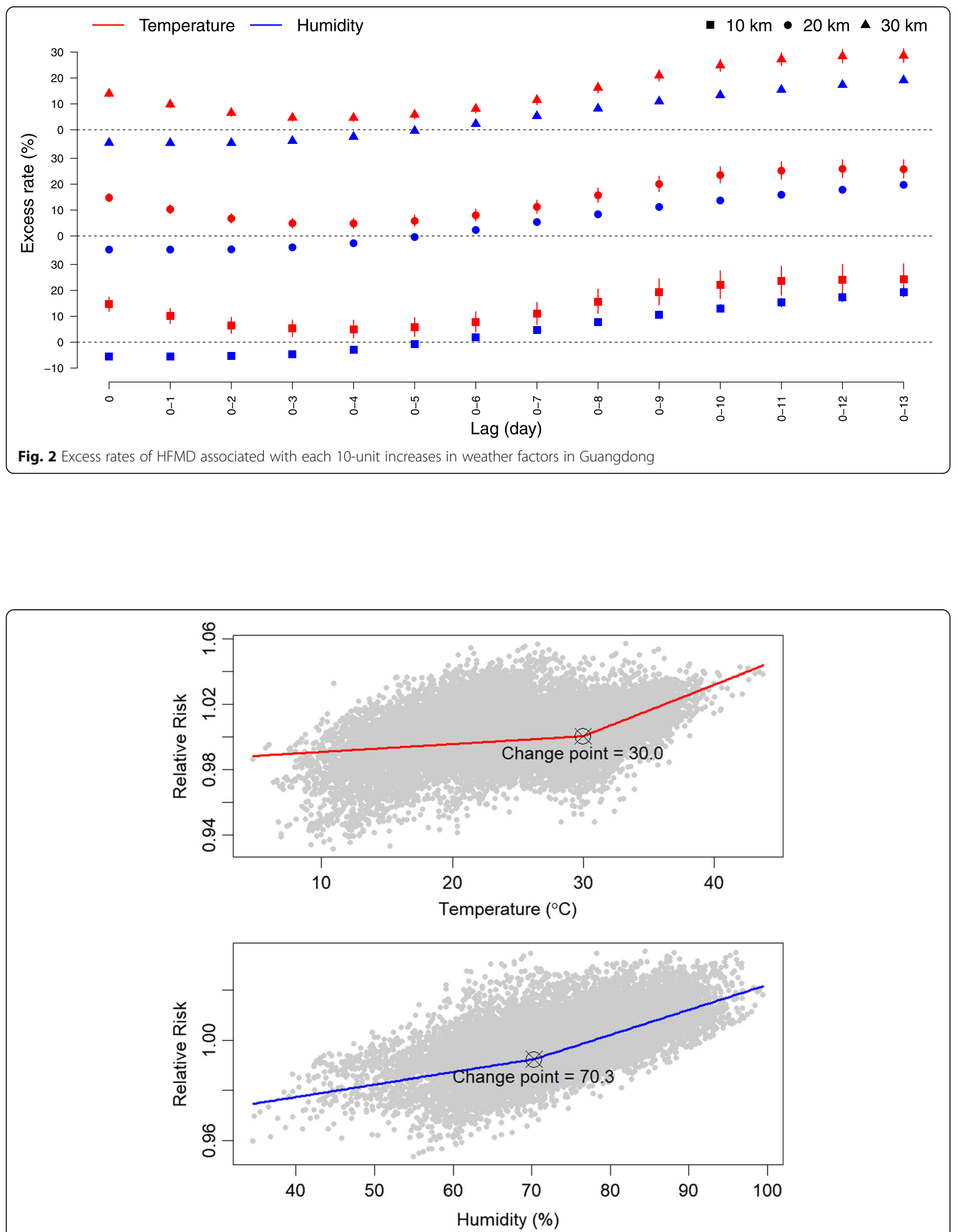

Fig. 3 Change point detection in association between HFMD and weather factors in Guangdong 
For the study population, the case characteristics were consistent with previous studies [3, 25]. Male children aged $\leq 3$ years old, and cared for at home tend to have higher infection rates. For the distribution of weather factors, our study differed from the previous studies by not reporting the weather by months, years, or even the whole study period $[7,26]$. Our study was the first to describe the weather factors by case periods and control periods using a case-crossover design.

For the effects of temperature, our study validated the results of previous studies. We found all excess rates of temperature across lag days were positive (3.0-9.6\%). One of our prior studies using Bayesian spatiotemporal model also reported that temperature (RR: 1.039; 95\% CI: $1.028,1.050)$ was statistically associated with HFMD [6]. The study by Onozuka et al. revealed that every $1{ }^{\circ} \mathrm{C}$ increase in average temperature increased by $11.2 \%$ for the weekly number of HFMD cases [27]. Higher temperature potentially enhances virus activity of HFMD and increases outdoor activities of children [9, 28].

For the effects of relative humidity, we found excess rates of relative humidity across lag days increased from a negative association $(-7.7 \%)$ to a positive association (1.9\%). Similar trends were also observed in a time-series study using negative binomial regression [27] and another study which used distributed lag non-linear model [29]. Another study by Wu et al. found a negative effect of relative humidity at lag 1 day and positive effects on lag 5-7 days [30]. Besides the evidence of 3-7 days of incubation period for HFMD, it may take time for an environment with higher relative humidity to culture enteroviruses and children's outdoor activities have the potential to be minimized during days with higher rainfall. Therefore, the positive effect on lag days 0-6 was more biologically plausible for both temperature and relative humidity.

For the subgroup analyses, we found males, children younger than 1 year of age, and home-care children were more sensitive to the effect of temperature and relative humidity. Consistent findings were also reported by one previous study [30]. More environment exposure and lower level of immunity for this susceptible group might be the potential reasons to cause a disease.

For the threshold effects, we detected change points for temperature $\left(30.0^{\circ} \mathrm{C}\right)$ and relative humidity $(70.3 \%)$ on HFMD. Which means more attention should be paid to temperature and relative humidity change points and strengthened early warning are an urgent need for susceptible population. A study by Hii et al. found higher risk of HFMD in maximum temperature above $32{ }^{\circ} \mathrm{C}$ and in rainfall above $75 \mathrm{~mm}$ [9]. One of the previous studies also reported the threshold effects of weather factors on HFMD in China, with the temperature greater than $24.85^{\circ} \mathrm{C}$ and the relative humidity between 80.59 and $82.55 \%$ [31]. Although different values were observed, both studies suggested higher temperature and higher relative humidity impose higher risk on HFMD.

For different distances of monitoring sites, we found a slightly increased rate of HFMD with both temperature and relative humidity from 10 to $30 \mathrm{~km}$. The further one was supposed to have more bias from exposure misclassification. So, our study showed that the associations would be overestimated if the weather factors were assigned without considering the distances of cases from the monitoring sites.

The present study stood out from prior studies by its strengths. First, this is the first study to estimate the weather effects on HFMD at the individual level using a case-crossover design, which can inherently control for demographic characteristics. Second, we limited the cases within a certain distance of monitoring sites to reduce bias from exposure misclassification.

However, several limitations of this study should also be acknowledged. First, a limited number (i.e., thirty-six) of meteorological monitoring sites were available, resulting in an undercounting of the cases in our study due to further distance than $30 \mathrm{~km}$. However, the distance of $30 \mathrm{~km}$ had included a large sample with $53.23 \%$ cases and the consistent findings from different distances (i.e., the statistically significant ERs were observed for both temperature and relative humidity since lag days 0-6) suggested that the effects of weather factors on HFMD will hardly change with the distance covering more cases. Second, the validity of HFMD reporting is usually a major concern in most vector-borne disease research. However, as HFMD data is a legislatively mandated database and all reporting persons have special certification, the likelihoods of inaccuracy and under-reporting are relatively small. Third, we didn't include tropical cyclones and air pollution due to the availability of the data. Further studies incorporating the multiple factors are needed. However, previous studies have suggested that the effects of air pollution on health are much lower than the effects of weather factors [32, 33]. And the relationship we observed between HFMD and the weather factors might be not substantially confounded by the air pollution. Finally, although we observed a significant association between HFMD and weather factors, the pathogenic mechanism still cannot be well understood.

\section{Conclusions}

Our study contributes to the limited knowledge of quantifying weather effects on HFMD at the individual level using a case-crossover design. Increased rates of HFMD were associated with increases in weather factors including temperature and relative humidity. Change points and lag effect were observed between weather factors and HFMD. Our study can serve as a reference for studying associations between diseases and environmental factors, and our findings are useful for targeted prevention and control of HFMD. 


\section{Supplementary information}

Supplementary information accompanies this paper at https://doi.org/10. 1186/s12879-019-4645-4.

Additional file 1: Table S1. Excess rates of HFMD associated with each 10-unit increases in weather factors by demographics on lag days 0-6 within $10 \mathrm{~km}$. Table S2. Excess rates of HFMD associated with each 10unit increases in weather factors by serotypes and lag days within $10 \mathrm{~km}$.

\section{Abbreviations}

Cl: Confidence interval; ER: Excess rates; HFMD: Hand, foot, and mouth disease; IQR: Interquartile range; SD: Standard deviation

\section{Acknowledgements}

We thank the China Center for Disease Control and Prevention for providing the data of notified hand, foot, and mouth disease cases.

\section{Authors' contributions}

ZD participated in the design, performed data analysis and interpretation, and drafted the manuscript. SL, TM, WZ, ZD and SY participated in the design and results interpretation, and helped to finalize the manuscript. TD performed data analysis and interpretation. YH participated in the design and supervised the study, participated in interpretation of results, and helped to finalize the manuscript. All authors have read and approved the contents of the final version.

\section{Funding}

This work was supported by the National Natural Science Foundation of China (No. 81473064 and 81773543). The sponsor had no role in the design, data collection, data analysis, data interpretation, or writing of the report.

\section{Availability of data and materials}

All weather data we used are available as an open source and can be acquired according to the provenance listed in the "Methods" section (http://data.cma.cn/). The cases data are available from China CDC (http://www.phsciencedata.cn/Share/en/index.jsp), which were used under license and not publicly available.

\section{Ethics approval and consent to participate}

Data were collected from the official HFMD surveillance system in China and no confidential information was involved. The research study protocol was approved by the Institutional Review Board at Sun Yat-sen University School of Public Health (No. 201415).

\section{Consent for publication}

Not applicable.

\section{Competing interests}

The authors declare that they have no competing interests.

\section{Author details}

${ }^{1}$ Department of Medical Statistics and Epidemiology, School of Public Health, Sun Yat-sen University, Guangzhou 510080, China. ²Department of Environmental Health Sciences, School of Public Health, University at Albany, State University of New York, Rensselaer, New York 12144, USA. ${ }^{3}$ Healthcare Department, Nanshan Maternity \& Child Healthcare Hospital of Shenzhen, Shenzhen 518000, China. ${ }^{4}$ Chinese Center for Disease Control and Prevention, Beijing 102206, China.

Received: 16 April 2019 Accepted: 22 November 2019

Published online: 03 December 2019

\section{References}

1. WHO. Hand, Foot and Mouth Disease Information Sheet. [Cited 2018-10-13]. Available from: http://www.wpro.who.int/emerging_diseases/hfmd. information.sheet/en/.

2. Yang S, Wu J, Ding C, Cui Y, Zhou Y, Li Y, Deng M, Wang C, Xu K, Ren J, et al. Epidemiological features of and changes in incidence of infectious diseases in China in the first decade after the SARS outbreak: an observational trend study. Lancet Infect Dis. 2017;17(7):716-25.
3. Du Z, Zhang W, Zhang D, Yu S, Hao Y. Epidemiological characteristics of severe cases of hand, foot, and mouth disease in Guangdong, China. Biostatistics Epidemiol. 2018;2(1):99-114.

4. Xiao X, Gasparrini A, Huang J, Liao Q, Liu F, Yin F, Yu H, Li X. The exposureresponse relationship between temperature and childhood hand, foot and mouth disease: a multicity study from mainland China. Environ Int. 2017;100:102-9.

5. Zhang W, Du Z, Zhang D, Yu S, Hao Y. Quantifying the adverse effect of excessive heat on children: an elevated risk of hand, foot and mouth disease in hot days. Sci Total Environ. 2016;541:194-9.

6. Du Z, Lawrence WR, Zhang W, Zhang D, Yu S, Hao Y. Bayesian spatiotemporal analysis for association of environmental factors with hand, foot, and mouth disease in Guangdong, China. Sci Rep-UK. 2018;8(1):15147.

7. Huang J, Chen S, Wu Y, Tong Y, Wang L, Zhu M, Hu S, Guan X, Wei S. Quantifying the influence of temperature on hand, foot and mouth disease incidence in Wuhan, Central China. Sci Rep-UK. 2018;8(1):1934.

8. Zhang W, Du Z, Zhang D, Yu S, Huang Y, Hao Y. Assessing the impact of humidex on HFMD in Guangdong Province and its variability across socialeconomic status and age groups. Sci Rep-UK. 2016;6:18965.

9. Hii YL, Rocklöv J, Ng N. Short term effects of weather on hand, Foot and Mouth Disease. PLoS One. 2011;6(2):e16796.

10. Du Z, Xu L, Zhang W, Zhang D, Yu S, Hao Y. Predicting the hand, foot, and mouth disease incidence using search engine query data and climate variables: an ecological study in Guangdong, China. BMJ Open. 2017:7:e16263.

11. Liao J, Yu S, Yang F, Yang M, Hu Y, Zhang J. Short-term effects of climatic variables on hand, foot, and mouth disease in mainland China, 2008-2013: a multilevel spatial Poisson regression model accounting for Overdispersion. PLoS One. 2016;11(1):e147054.

12. Zhang W, Lin S, Hopke PK, Thurston SW, van Wijngaarden E, Croft D, Squizzato S, Masiol M, Rich DQ. Triggering of cardiovascular hospital admissions by fine particle concentrations in New York state: before, during and after implementation of multiple environmental policies and a recession. Environ Pollut. 2018;242:1404-16.

13. Bateson TF, Coull BA, Hubbell B, Ito K, Jerrett M, Lumley T, Thomas D, Vedal $S$, Ross M. Panel discussion review: session three - issues involved in interpretation of epidemiologic analyses - statistical modeling. J Expo Sci Env Epid. 2007:17:590-6.

14. Zeger SL, Thomas D, Dominici F, Samet JM, Schwartz J, Dockery D, Cohen A. Exposure measurement error in time-series studies of air pollution: concepts and consequences. Environ Health Perspect. 2000;108(5):419-26.

15. Evans KA, Hopke PK, Utell MJ, Kane C, Thurston SW, Ling FS, Chalupa D, Rich DQ. Triggering of ST-elevation myocardial infarction by ambient wood smoke and other particulate and gaseous pollutants. J Expo Sci Env Epid. 2016:27:198-206.

16. Levin KA. Study design VI - ecological studies. Evid Based Dent. 2006;7(4):108

17. Levy D, Lumley T, Sheppard L, Kaufman J, Checkoway H. Referent selection in case-crossover analyses of acute health effects of air pollution. Epidemiology. 2001;12(2):186-92.

18. Rich DQ, Utell MJ, Croft DP, Thurston SW, Thevenet-Morrison K, Evans KA, Ling FS, Tian Y, Hopke PK. Daily land use regression estimated woodsmoke and traffic pollution concentrations and the triggering of ST-elevation myocardial infarction: a case-crossover study. Air Qual Atmos Health. 2018; $11(2): 239-44$.

19. Shah ASV, Lee KK, McAllister DA, Hunter A, Nair H, Whiteley W, Langrish JP, Newby DE, Mills NL. Short term exposure to air pollution and stroke: systematic review and meta-analysis. BMJ. 2015;350:h1295.

20. Xing W, Liao Q, Viboud C, Zhang J, Sun J, Wu JT, Chang Z, Liu F, Fang VJ, Zheng $Y$, et al. Hand, foot, and mouth disease in China, 2008-12: an epidemiological study. Lancet Infect Dis. 2014;14(4):308-18.

21. Wikipedia. Baidu Maps. [Cited 2018-10-09]. Available from: https://en. wikipedia.org/wiki/Baidu_Maps\#Coordinate_system.

22. Chen $C$, Lin H, Li X, Lang L, Xiao X, Ding P, He P, Zhang Y, Wang M, Liu Q Short-term effects of meteorological factors on children hand, foot and mouth disease in Guangzhou, China. Int J Biometeorol. 2014;58(7):1605-14.

23. Yang Z, Zhang Q, Cowling BJ, Lau EHY. Estimating the incubation period of hand, foot and mouth disease for children in different age groups. Sci RepUK. 2017:7(1):16464

24. Toms JD, Lesperance ML. Piecewise regression: a tool for identifying ecological thresholds. Ecology. 2003:84(8):2034-41.

25. Deng T, Huang Y, Yu S, Gu J, Huang C, Xiao G, Hao Y. Spatial-temporal clusters and risk factors of hand, foot, and mouth disease at the district level in Guangdong Province, China. PLoS One. 2013;8(2):e56943. 
26. Wang P, Goggins WB, Chan EYY. Hand, foot and mouth disease in Hong Kong: a time-series analysis on its relationship with weather. PLoS One. 2016;11(8):e161006.

27. Onozuka D, Hashizume M. The influence of temperature and humidity on the incidence of hand, foot, and mouth disease in Japan. Sci Total Environ. 2011:410-411:119-25.

28. Zhu L, Yuan Z, Wang X, Li J, Wang L, Liu Y, Xue F, Liu Y. The impact of ambient temperature on childhood HFMD incidence in inland and coastal area: a Two-City study in Shandong Province, China. Int J Env Res Pub He. 2015;12(8):8691-704.

29. Yang $\mathrm{H}, \mathrm{Wu} J$, Cheng J, Wang $\mathrm{X}$, Wen L, Li K, Su H. Is high relative humidity associated with childhood hand, foot, and mouth disease in rural and urban areas? Public Health. 2017;142:201-7.

30. Wu H, Wang $\mathrm{H}$, Wang $\mathrm{Q}$, Xin Q, Lin $\mathrm{H}$. The effect of meteorological factors on adolescent hand, foot, and mouth disease and associated effect modifiers. Glob Health Action. 2014;7:24664.

31. Du Z, Zhang W, Zhang D, Yu S, Hao Y. The threshold effects of meteorological factors on hand, foot, and mouth disease (HFMD) in China, 2011. Sci Rep. 2016;6:36351.

32. Chen R, Yin P, Wang L, Liu C, Niu Y, Wang W, Jiang Y, Liu Y, Liu J, Qi J, et al. Association between ambient temperature and mortality risk and burden: time series study in 272 main Chinese cities. BMJ. 2018:363:k4306.

33. Xie H, Yao Z, Zhang Y, Xu Y, Xu X, Liu T, Lin H, Lao X, Rutherford S, Chu C, et al. Short-term effects of the 2008 cold spell on mortality in three subtropical cities in Guangdong Province, China. Environ Health Perspect. 2013;121(2):210-6.

\section{Publisher's Note}

Springer Nature remains neutral with regard to jurisdictional claims in published maps and institutional affiliations.

Ready to submit your research? Choose BMC and benefit from:

- fast, convenient online submission

- thorough peer review by experienced researchers in your field

- rapid publication on acceptance

- support for research data, including large and complex data types

- gold Open Access which fosters wider collaboration and increased citations

- maximum visibility for your research: over $100 \mathrm{M}$ website views per year

At BMC, research is always in progress.

Learn more biomedcentral.com/submissions 